\title{
BLOCK GRAPHS WITH LARGE PAIRED DOMINATION MULTISUBDIVISION NUMBER
}

\author{
Christina M. Mynhardt \\ Department of Mathematics and Statistics \\ University of Victoria \\ Victoria BC, Canada \\ e-mail: kieka@uvic.ca \\ AND \\ JOANNA RACZEK \\ Faculty of Applied Physics and Mathematics \\ Gdansk University of Technology \\ ul. Narutowicza 11/12, 80-233 Gdańsk, Poland \\ e-mail: joanna.raczek@pg.edu.pl
}

\begin{abstract}
The paired domination multisubdivision number of a nonempty graph $G$, denoted by $\operatorname{msd}_{\mathrm{pr}}(G)$, is the smallest positive integer $k$ such that there exists an edge which must be subdivided $k$ times to increase the paired domination number of $G$. It is known that $\operatorname{msd}_{\mathrm{pr}}(G) \leq 4$ for all graphs $G$. We characterize block graphs with $\operatorname{msd}_{\mathrm{pr}}(G)=4$.

Keywords: paired domination, domination subdivision number, domination multisubdivision number, block graph.
\end{abstract}

2010 Mathematics Subject Classification: 05C69.

\section{REFERENCES}

[1] M. Atapour, A. Khodkar and S.M. Sheikholeslami, Characterization of double domination subdivision number of trees, Discrete Appl. Math. 155 (2007) 1700-1707. doi:10.1016/j.dam.2007.03.007

[2] M. Dettlaff and J. Raczek, Paired domination multisubdivision numbers of graphs, submitted. 
[3] M. Dettlaff, J. Raczek and J. Topp, Domination subdivision and domination multisubdivision numbers of graphs, Discuss. Math. Graph. Theory 39 (2019) 829-839. doi:10.7151/dmgt.2103

[4] O. Favaron, H. Karami and S.M. Sheikholeslami, Connected domination subdivision numbers of graphs, Util. Math. 77 (2008) 101-111.

[5] O. Favaron, H. Karami and S.M. Sheikholeslami, Paired-domination subdivision numbers of graphs, Graphs Combin. 25 (2009) 503-512. doi:10.1007/s00373-005-0871-1

[6] T.W. Haynes, S.M. Hedetniemi, S.T. Hedetniemi, J. Knisely and L.C. van der Merwe, Domination subdivision numbers, Discuss. Math. Graph Theory 21 (2001) 239-253.

doi:10.7151/dmgt.1147

[7] T.W. Haynes, M.A. Henning and L.S. Hopkins, Total domination subdivision numbers of graphs, Discuss. Math. Graph Theory 24 (2004) 457-467. doi:10.7151/dmgt.1244

[8] T.W. Haynes, S.T. Hedetniemi and P.J. Slater, Fundamentals of Domination in Graphs (Marcel Dekker Inc., New York, 1998).

[9] T.W. Haynes, S.T. Hedetniemi and L.C. van der Merwe, Total domination subdivision numbers, J. Combin. Math. Combin. Comput. 44 (2003) 115-128.

[10] A. Khodkar, B.P. Mobaraky and S.M. Sheikholeslami, Upper bounds for the Roman domination subdivision number of a graph, AKCE Int. J. Graphs Comb. 5 (2008) $7-14$.

[11] S. Velammal, Studies in Graph Theory: Covering, Independence, Domination and Related Topics, Ph.D. Thesis (Manonmaniam Sundaranar University, Tirunelveli, 1997).

Received 27 June 2018

Revised 28 December 2018

Accepted 16 May 2019 